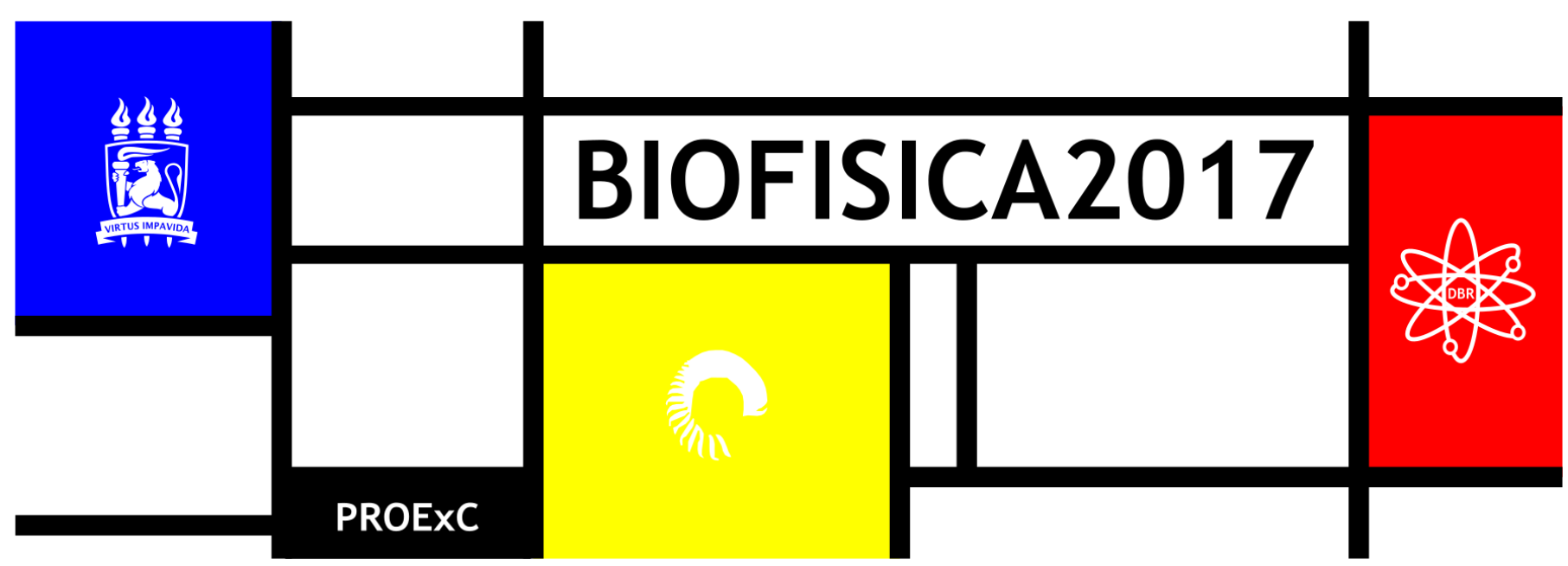

\title{
ELEMENTOS QUÍMICOS TRAÇADORES DA INFLUÊNCIA MARINHA NA REGIÃO METROPOLITANA DO RECIFE
}

\author{
Thiago Oliveira dos Santos*, Thiago Moura da Rocha Bastos, Clovis Abrahão Hazin, Elvis Joacir De França
}

CRCN-NE/CNEN

E-mail:*thiago_cbufpe@yahoo.com.br

\begin{abstract}
INTRODUÇÃO
A diminuição da qualidade do ar em grandes centros urbanos é um dos principais problemas de saúde pública, pois o incremento de elementos químicos na atmosfera urbana por atividades antropogênicas é apontado como agente causador ou agravante de doenças preexistentes na população exposta, em especial de crianças e idosos (BRAGA, 2015). Em regiões costeiras, como a Região Metropolitana do Recife (RMR), a proximidade com o mar acaba proporcionando tanto a dispersão quanto o incremento de alguns elementos químicos característicos. Neste contexto, tornase necessário o desenvolvimento de estudos para identificar os mecanismos envolvidos na distribuição de elementos químicos e suas prováveis fontes. A monitoração de uma área extensa como a RMR é uma atividade extremamente complexa. Monitores mecânicos podem ser utilizados, no entanto, o elevado custo financeiro é um fator limitante. Uma alternativa eficaz e menos onerosa é a biomonitoração. Induzindo liquens e plantas epífitas (SANTOS, et al., 2013; CLOQUET et al., 2015). Esses organismos possuem a habilidade de adquirir a água e os nutrientes necessários ao seu desenvolvimento a partir da atmosfera, além disso são capazes de acumular elementos químicos em seus tecidos refletindo assim as concentrações ambientais (PIGNATA et al., 2008). O objetivo deste trabalho é verificar utilização de $\mathrm{Cl}$ e $\mathrm{Mg}$, como elementos químicos traçadores da influência marinha na atmosfera urbana da Região Metropolitana do Recife.
\end{abstract}

\section{MATERIAL E MÉTODOS}

\section{Biomonitoração ativa}

O líquen Cladonia verticillaris foi obtido na cidade de Alhandra no Estado da Paraíba enquanto que a coleta da Tillandsia recurvata foi realizada em Gravatá, no Estado de Pernambuco, ambos os locais em áreas de vegetação nativa e distantes de fontes antropogênicas de elementos químicos. No laboratório, foram preparadas as unidades experimentais compostas por cerca de $12 \mathrm{~g}$ de ambos biomonitores acondicionados em bolsas de nylon $\left(20 \mathrm{~cm}^{2}\right)$ com abertura de malha que permite sua exposição à atmosfera (Figura 1). As unidades experimentais foram transplantadas em 40 pontos da RMR a uma altura de aproximadamente $2 \mathrm{~m}$ do solo por um período de seis meses.



Figura 1. Unidades experimentais de Cladonia verticilaris (a) e Tillandsia recurvata (b)

Preparação e análise

As amostras foram secas em estufa à $60^{\circ} \mathrm{C}$, até peso constante, cominuídas até o tamanho máximo de partículas de $1 \mathrm{~mm}$ e homogeneizadas. Porções de $0,5 \mathrm{~g}$ foram colocadas em cápsulas de teflon e analisadas pela Fluorescência de Raios-X por Dispersão de Energia (EDXRF). Para a demonstração da qualidade do procedimento analítico, porções teste do material de referência IAEA-336 e material de referência certificado SRM-1547 foram analisadas com as amostras. As análises foram realizadas em atmosfera vácuo (menor que $30 \mathrm{~Pa}$ ) com voltagens variando de $5 \mathrm{kV}$ para elementos químicos leves e $50 \mathrm{kV}$ para elementos químicos pesados, todas em triplicata (SOUZA et al.,2013).

Mapas de distribuição

A partir das concentrações obtidas nos biomonitores e utilizando o programa Surfer 11, foram obtidos mapas de distribuição para os elementos químicos traçadores $\mathrm{Cl}$ e $\mathrm{Mg}$.

\section{RESULTADOS E DISCUSSÃO}

A qualidade do procedimento analítico foi comprovada a partir dos resultados obtidos para os materiais de referência a nível de $95 \%$ de confiança. As concentrações dos traçadores da influência do spray marinho na distribuição e dispersão de elementos químicos 
para a atmosfera urbana da RMR foram quantificadas nos organismos biomonitores transplantados. Estes apresentaram concentrações entre 160 a $42000 \mathrm{mg} \mathrm{kg}^{-1}$, com a média de $3600 \mathrm{mg} \mathrm{kg}^{-1}$ para o elemento químico $\mathrm{Cl}$ nos exemplares de Cladonia verticillaris e entre 800 a $8600 \mathrm{mg} \mathrm{kg}^{-1}$ com concentração média de $2500 \mathrm{mg} \mathrm{kg}^{-1}$ para o $\mathrm{Mg}$ nos exemplares da bromélia atmosférica Tillandsia recurvata. Regiões litorâneas como a RMR sofrem uma forte influência marinha. O spray marinho pode atuar fornecendo elementos químicos para a atmosfera urbana (ex. $\mathrm{Cl}$ e $\mathrm{Mg}$ ), e a partir da ação do vento, auxiliar no transporte e dispersão de poluentes. Os mapas de distribuição dos elementos químicos construídos permitem identificar que os biomonitores transplantados próximos à costa apresentaram maiores concentrações dos elementos traçadores $\mathrm{Cl}$ e $\mathrm{Mg}$ em seus tecidos que aqueles organismos transplantados em locais distantes (Figuras 3 e 4 ).



\section{CONCLUSÕES}

Existe uma relação entre as concentrações de $\mathrm{Cl}$ e $\mathrm{Mg}$ obtidas nos organismos transplantados e a proximidade com a costa marinha corroborando com a hipótese de que o spray marinho é a principal fonte desses elementos químicos na RMR. Os resultados obtidos fornecem informações relevantes para futuras pesquisas a respeito da distribuição de concentração de elementos químicos na atmosfera urbana da RMR.

\section{REFERÊNCIAS}

BRAGA, A.L.F., PEREIRA, L.A.A., PROCÓPIO, M., ANDRÉ, P.A., SALDIVA, P.H.N. Associação entre poluição atmosférica e doenças respiratórias e cardiovasculares na cidade de Itabira, Minas Gerais, Brasil. Cad. Saúde Pública, Rio de Janeiro, 23 Sup. 4570 - 578, 2007.

CLOQUET, C.; ESTRADE, N.; CARIGNAN, J. Ten years of elemental atmospheric metal fallout and $\mathrm{Pb}$ isotopic composition monitoring using lichens in northeastern France. Comptes Rendus Geoscience v.347 p. 257-266, 2015.

PIGNATA, M.L., GONZÁLES, C.M., CARRERAS, H.A., WANNAZ, E.D. Guía para el muestreo de líquenes y plantas epífitas que se emplean como biomonitores de acumulación de metales pesados y elementos traza em latinoamérica. IAEA TECHNICAL CO-OPERATION PROJECT: RLA/2/013. 2008.

SANTOS, T.O., HONORATO, R.V., SILVA-FILHO, C.A., HAZIN, C.A., VALENTIM, E., 2013. Quantification of chemicals elements associated with vehicle traffic on atmospheric bromeliads transplanted in the Metropolitan Region of Recife. Scientia Plena v. 9 , n. 8 (081017-1).

SOUSA, E. E.; PAIVA, J. D. S.; FRANÇA, E. J.; ALMEIDA, M. E. S.; CANTINHA, R. S.; HAZIN, C. A. Qualidade nas análises químicas de matrizes biológicas pela fluorescência de raios-X por dispersão de energia. In: International Nuclear Atlantic Conference - INAC 2013

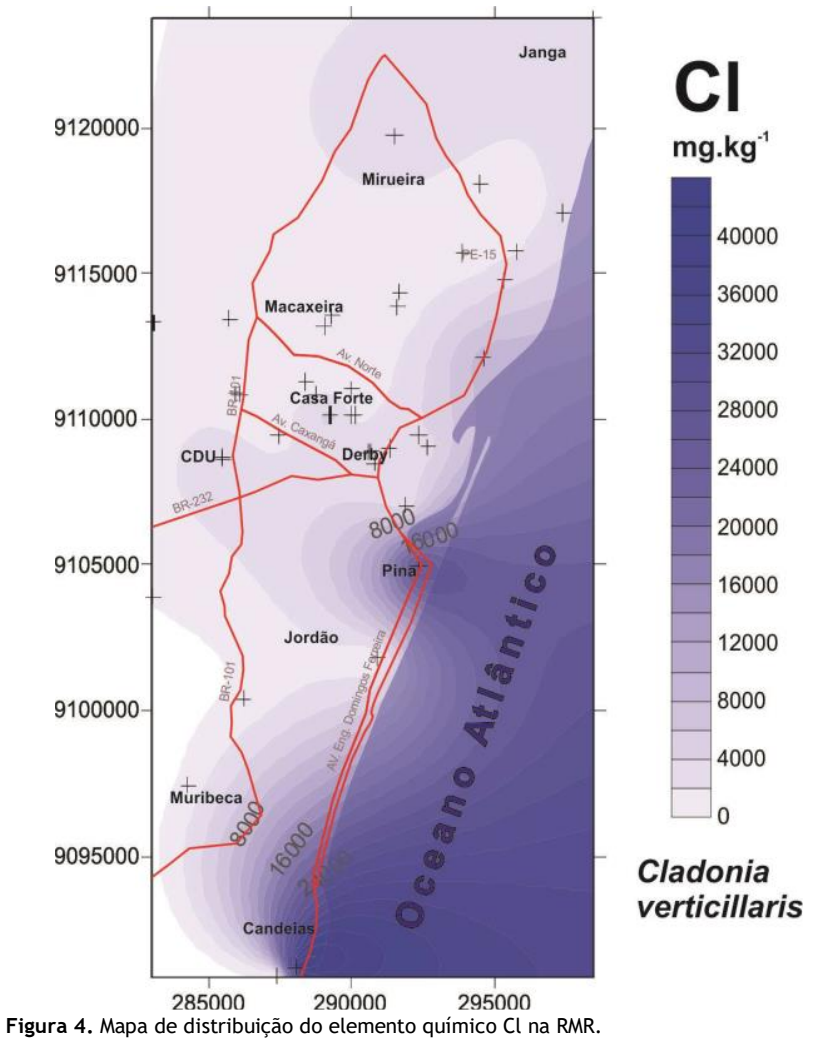

